\title{
An Application of Optimal Design Method on Horizontal Wellbore Length Design
}

\author{
Yueting $\mathrm{Hu}$ \\ China National Petroleum Corporation, China \\ No.9 Dong Zhi Men Beidajie, Beijing 100007, China \\ Tel: 86-10-5998-2571 E-mail: huyueting@petrochina.com.cn
}

\begin{abstract}
The paper presents an example of the horizontal wellbore length design through the application of a modified optimal design method. Two different models were developed to tackle the issues of distinct cases through application of the method. In the course of analyzing the models, a qualitative conclusion could be reached that the optimal length of horizontal wells drilled together with vertical wells are always longer than that of horizontal wells only which are being drilled.
\end{abstract}

Keywords: Horizontal well, Optimal design, NPV (net present value)

\section{Introduction}

At the beginning of the development of horizontal well technology, the length of a horizontal wellbore could be drilled no longer than a few hundred meters. The longer the horizontal wellbore is drilled, the more oil is extracted. The existence of this horizontal wellbore makes the horizontal well to have an advantage over the vertical one. The cost of drilling a horizontal wellbore is much more than that spent on a vertical well, therefore the horizontal well can only maximize its economic efficiency as compared to the vertical well if its horizontal wellbore is drilled long enough. This is the main reason why more effort had been exhausted on the technology on how to get drill a longer horizontal wellbore at the early stage of the development of horizontal well-drilling technology. Through years of painstaking effort, great progress has been made in this respect. The horizontal wellbore can be drilled up to full reservoir length (Moritis, 1990, pp52-58). Such questions need to be addressed: Is it necessary to drill so long a horizontal wellbore? Is there an optimal horizontal wellbore length and how could it be made efficient if it does exist?

With the notion of prolonging a horizontal wellbore length, more and more oil is produced. But the increase of oil production is not proportional to the increase of a horizontal wellbore length due to the friction within the wellbore and some other causes. The pressure drop caused by the friction within the wellbore will be great enough to prevent the oil production to rise any more if the horizontal wellbore length is drilled excessively long (Dikken, 1990, pp63-67) (Novy,1995). On the other hand, with the prolonging of horizontal wellbore length, the cost spent will increase rapidly. One reason behind this is that with the increase of horizontal wellbore length, the wellbore profile changes accordingly which leads to the increase in well-drilling cycle and well casings, both of which covers a great portion in well-drilling cost. The other reason is that the procedure's complexity increases with the prolonging of horizontal wellbore length, which may lead to a great deal in the increase of both the cost of risk and the cost of daily drilling. Combining all the above-mentioned reasons, it can be seen that the well-drilling cost will increase greatly if the horizontal wellbore is drilled excessively long. Figure 1 illustrates a census curve on the change of drilling cost per foot in relation with the increase of horizontal wellbore length as drawn by an American oil company.

\section{Insert Figure 1 Here}

Based on the above analysis, a conclusion can be drawn that an economically optimal length does exist if a horizontal wellbore is drilled long enough. Currently, with the development of horizontal well drilling technology, the horizontal wellbore length can be drilled longer than the exact prescribed length, which means there is a need to optimize the horizontal wellbore length in order to get more economic efficiency. In addition, because the horizontal wells are always drilled as development wells instead of wildcat wells, the reservoir data in the oilfield can be obtained more accurately through historical data matching. And with the technology of reservoir numerical simulation, the production of a horizontal well with a certain horizontal wellbore length can be predicted accurately enough, which in turn, will enable us to calculate and compare the import and export of the horizontal well data with different horizontal wellbore lengths. Therefore, aside from being a necessity, it is also feasible to work out the optimal horizontal wellbore length. 


\section{Theoretical Model}

With the horizontal wellbore being drilled longer, more attention is being paid on its optimal issues. Numerous research papers on the optimal design of horizontal wellbore length have been published in recent years. However, most of them dealt with the problem not holistically but rather on single-sided perspective, which is either from the perspective of the reservoir or from that of drilling engineering, and others. These may only act as one of the constraining factors, but not as the objective function. A horizontal well may have much advantage over a vertical one, but the primary advantage lies in its higher economic efficiency, hence the economic indexes should be used as the objective function when developing an optimal model. Some papers do analyze the problem from an economic point of view (Hyun,2003) (Zhifei,1997,pp70-75) (Guanmin,2008), but either the economic indexes they chose or the appraisal methods they use were questionable, which might have an effect on the results, if not lead to a wrong conclusion. A typical case is that the NPV of a scale-variable project such as a horizontal well is always taken as an objective function when building a optimal model, but the objective function lacks further efficiency constraint, which means the scale of a project (such as building height, road width, horizontal wellbore length, etc.) will be the optimal focus when its NPV gets the maximum value. In fact, the scale with maximum NPV of a project is usually not the economically optimal scale of the project but the maximum one. The economically optimal scale can be only restricted within the range in which NPV \& NPVR have their maximum values as its upper and lower limits respectively, and the economically optimal scale within the range can only be worked out according to the specific case. I have expounded and have proven the above mentioned perspective in the papers "On the Best Investment Scale Design for Construction Projects" (Yueting, 1995, pp92-96) and "On the Design Method of Economically Optimal Scale of Projects" (Yueting, 2010, pp210-217)specifically. In the latter research document, I dealt with the economically optimal scale design issue in two models in accordance to different cases. These two optimal models would be presented and used in this paper to analyze the optimal issue of horizontal wellbore length design.

Case A: An oilfield is developed by both horizontal and vertical wells

In order to simplify problem at hand, it is assumed that the NPV of a horizontal well is the function of the variable L, the length of reservoir developed by a horizontal well with a horizontal wellbore of that length, i.e., $\mathrm{NPV}=\mathrm{f}(\mathrm{L})$.

Based on the above analysis, a horizontal well with an adjustable horizontal wellbore belongs to a scale-variable project, and the changes on a scale-variable project follows the rule of decreasing returns to scale. When a horizontal wellbore has started to be drilled, the cost it takes is much more than that of a vertical well, and the production it gets is not great enough to cover for the cost it consumes as compared to a vertical well, therefore, the NPV and NPV/L of horizontal well are both negative and smaller than those of a vertical well at the very beginning. At the time when the horizontal section is being drilled, its advantage would be visible, the rate of oil-production increase more rapidly than that of the cost, so its $\mathrm{dNPV} / \mathrm{dL}$ increases faster leading to an immediate increase of NPV and NPV/L. With the horizontal wellbore being drilled longer, the wellbore friction has effects on the production and there would be a rapid increase on the well-drilling cost, which makes the NPV increase at a low rate. When the horizontal wellbores drilled become excessively long, their effect will become so great that the NPV of the horizontal well will start to decline. In this way, the curve between the horizontal wellbore length $\mathrm{L}$ and the NPV of the horizontal well can be drawn as Figure 2. The curve of NPV-L is quite similar to the curve of NPV - C (the relationship between NPV and the capital invested in a project) (Jiaji, 1996, pp60-61), the only difference is the horizontal axis, it is the reservoir length $\mathrm{L}$ that a horizontal well develops rather than the capital $\mathrm{C}$ a project takes, the capital invested under this condition is supposed to be limitless. In Figure 2, the curve of NPV $-\mathrm{L}$ is the above one, the others below are the curves of dNPV/dL $-\mathrm{L}$ and NPV/L $-\mathrm{L}$ of the horizontal well respectively, the curves of $\mathrm{dNPV} / \mathrm{dL}-\mathrm{L}$ comes across with that of NPV/L $-\mathrm{L}$ just at its maximum point. Yueting (1995, pp92-96) published a paper to explain the relationship among NPV, NPVR \& $\mathrm{dNPV} / \mathrm{dL}$ of a normal production function in the year 1995. A vertical well is a well drilled perpendicularly through the oil reservoir and covers a certain area however it is drilled. This means that a vertical well develops a certain amount of oil reservoir and produces a certain amount of oil. Moreover, the capital it takes is fixed, therefore, its NPV is fixed, and its NPV/L, dNPV/dL are the same and constant, so the curve of NPV/L-L \& $\mathrm{dNPV} / \mathrm{dL}-\mathrm{L}$ of a vertical well can be drawn as a straight line, JC in Figure 2. Contrary to the nature of a vertical well, a horizontal well is rather changeable, its $\mathrm{dNPV} / \mathrm{dL}, \mathrm{NPV}$, and NPV/L are all changed and dependent to the prolonging of the horizontal wellbore, which was described in the discussion above.

Insert Figure 2 Here

With the horizontal wellbore prolonging, the curve of $\mathrm{dNPV} / \mathrm{dL} — \mathrm{~L}$ of the horizontal well initially intersects the 
curve of NPV/L- $\mathrm{L}$ of the horizontal well at the maximum point $\mathrm{A}$, and then intersects the perpendicular line, the curve of $\mathrm{dNPV} / \mathrm{dL}-\mathrm{L}$ of the vertical well, at point B. From this point, continuous drilling of the horizontal wellbore will get less NPV than stopping to drill vertical wells instead, for the value of dNPV/dL of the horizontal well falls below that of the vertical well after point B, even though the NPV of the horizontal well is still increasing at a low rate (Figure 2). Therefore, it is at the point B that an optimal horizontal wellbore should be stopped in order to get the maximum value of NPV on the project portfolio with a certain amount of resource being consumed. If the horizontal wellbore keeps on being drilled to the point F, where the NPV of the horizontal well itself gets the maximum value, the length of the horizontal at the point $\mathrm{F}$ is not the optimum length but the upper limit, i.e., the maximum length. Because the $\mathrm{dNPV} / \mathrm{dL}$ of the horizontal well comes to zero which falls far below that of the vertical well at the point $\mathrm{F}$, i.e., $(\mathrm{dNPV} / \mathrm{dL})_{\mathrm{V}}=\mathrm{FH}>(\mathrm{dNPV} / \mathrm{dL})_{\mathrm{H}}=0$. It means, on one hand, that the scale is at its peak, and it should not be increased further, otherwise its NPV will decrease instead of increase, so it should be set as the upper limit. On the other hand, the total NPV of the project portfolio is not the maximum due to the reason that the $\mathrm{dNPV} / \mathrm{dL}$ of the horizontal well with that horizontal wellbore length is less than that of the vertical wells, and the total NPV of the project portfolio will increase even more if starting to drill vertical wells instead of keeping on drilling the horizontal wellbore from point $\mathrm{B}$, so it is not the optimal length. Therefore, the length of the horizontal wellbore at the point $\mathrm{F}$ is not the optimum length but the upper limit. At the point F, although the marginal increment of NPV of the horizontal well is below that of the vertical well, the NPV/L of the horizontal well is still greater than that of the vertical well, i.e. $\mathrm{MH}>\mathrm{FH}$, therefore the total NPV of the horizontal well is still greater than that of the vertical wells with the same amount of resource being consumed (Figure 2). It means that the oil reservoir developed by a horizontal well with a long horizontal length can still get a greater NPV than that developed by vertical wells, as long as its horizontal length does not exceed the point $\mathrm{C}$, even though its length has already overtaken the point $\mathrm{F}$. If the horizontal wellbore keeps on drilling overpass point C, not only the marginal increment of NPV but also the NPV/L of the horizontal well will be both smaller than those of the vertical well. It means that the oil reservoir developed by vertical wells will get more NPV than that developed by a long horizontal well with its terminal point surpassing the point C.

As stated above, in order to get more NPV from a certain amount of resource, the length of the horizontal wellbore should be stopped at the point B (Figure 2), where the marginal increment of NPV of the horizontal well is equal to that of the vertical well, rather than keep on drilling until the point F, where the NPV of the horizontal well itself comes to the maximum value, let alone up to the point $\mathrm{C}$. The analysis above shows that the point at which the marginal increment of NPV of the horizontal well is equal to that of the vertical well is the intersecting point for the optimal horizontal wellbore length design. Therefore, the $\mathrm{dNPV} / \mathrm{dL}$ of the vertical well must be used as the designated efficiency constraint when the design model for optimal horizontal wellbore length is set up, without which the horizontal wellbore length may be designed excessively long to still serve as the optimal length.

Supposed the length of resource covered by one vertical well is $\Delta \mathrm{L}$, the horizontal wellbore length of a horizontal well should be at least $\mathrm{L}_{\min }$, otherwise the income generated from a horizontal well could not cover for the cost spent on a horizontal well, the largest length is named as $\mathrm{L}_{\max }$ which may be limited by the scale of the oil reservoir, the wellbore friction effect on production, the capacity of the rig used, or the technology of drilling, etc. In order to enlarge the NPV of the horizontal well with a certain amount of resource consumed, the drilling of this horizontal wellbore should be stopped as soon as its $\mathrm{dNPV} / \mathrm{dL}$ is not greater than that of a vertical one, i.e.:

$$
\{\mathrm{dNPV}(\mathrm{L}) / \mathrm{dL}\}_{\mathrm{H}} \geq(\mathrm{dNPV} / \mathrm{dL})_{\mathrm{V}}
$$

Or, $\mathrm{NPV}_{\mathrm{H}}(\mathrm{L}+\Delta \mathrm{L})-\mathrm{NPV}_{\mathrm{H}}(\mathrm{L}) \geq \mathrm{NPV}_{\mathrm{V}}$

Here, $\mathrm{NPV}_{\mathrm{H}} \& \mathrm{NPV}_{\mathrm{V}}$ stands for the NPV of a horizontal well and that of a vertical well respectively.

Therefore, the model can be expressed as:

Objective function:

$\operatorname{NPV}(\mathrm{L})=\operatorname{Max}\left\{\Sigma_{\mathrm{i}=1}{ }^{\mathrm{m}}[\mathrm{CI}(\mathrm{L})-\mathrm{CO}(\mathrm{L})]_{\mathrm{t}} /(1+\mathrm{i})^{\mathrm{t}}\right\}$

Constraint condition:

$$
\begin{aligned}
& \mathrm{NPV}_{\mathrm{H}}(\mathrm{L}+\Delta \mathrm{L})-\mathrm{NPV}_{\mathrm{H}}(\mathrm{L}) \geq \mathrm{NPV}_{\mathrm{V}} \quad\left(\text { while, } \mathrm{d}^{2}\left\{\mathrm{NPV}_{\mathrm{H}}(\mathrm{L})\right\} / \mathrm{dL}^{2}<0\right) \\
& \mathrm{L}_{\text {max }} \geq \mathrm{L} \geq \mathrm{L}_{\text {min }}
\end{aligned}
$$

Here, $\mathrm{CI}(\mathrm{L}), \mathrm{CO}(\mathrm{L})$ stands for the input \& output of the cash flow of a horizontal well with $\mathrm{L}$ meters horizontal 
wellbore length every year respectively, and $m$ is the appraisal time of horizontal wells. The reason for the necessity of the constraint $\mathrm{d}^{2}\left\{\mathrm{NPV}_{\mathrm{H}}(\mathrm{L})\right\} / \mathrm{dL}^{2}<0$, after the constraint condition $\mathrm{NPV}_{\mathrm{H}}(\mathrm{L}+\Delta \mathrm{L})-\mathrm{NPV}_{\mathrm{H}}(\mathrm{L}) \geq \mathrm{NPV}$, will be explained in the section of "Model Analysis".

\section{Case B: An oilfield is developed by horizontal wells}

If an oilfield is developed only by horizontal wells, then the special constraint that the marginal increment of NPV of a vertical is no less than that of a horizontal well will no longer exist. In order to get the maximum value of NPV, it is recommended that when an optimal scale is designed, both the project of which scale optimization is needed and the potential projects that are feasible in that certain condition should be taken into account. In other words, it is the NPV of the project portfolio not that of the single project itself should be regarded as the objective function when an optimal model for economically optimal scale is set in order to get the maximum NPV value.

For instance, there are $n$ horizontal wells placed in an oilfield, the relationship between the total NPV of the project portfolio and the NPV/L of a single well can be expressed:

$$
\operatorname{NPV}(\mathrm{L})=\sum_{\mathrm{i}=1}{ }^{{ }^{\prime}}\left\{[\mathrm{NPV}(\mathrm{L}) / \mathrm{L}]_{\mathrm{i}} \times \mathrm{L}_{\mathrm{i}}\right\}
$$

Here, $\mathrm{L}_{1}+\mathrm{L}_{2}+\mathrm{L}_{3}+\ldots \ldots+\mathrm{L}_{\mathrm{i}}+\ldots \ldots+\mathrm{L}_{\mathrm{n}}=\mathrm{L}$

And, $\mathrm{L}_{1}=\mathrm{L}_{2}=\mathrm{L}_{3}=\ldots \ldots=\mathrm{L}_{\mathrm{i}}=\ldots \ldots=\mathrm{L}_{\mathrm{n}}$

Therefore, $\mathrm{L}_{\mathrm{i}}=\mathrm{L} / \mathrm{n}$

Then, the objective function can be written as:

$$
\operatorname{NPV}(\mathrm{L})=\operatorname{Max}\left\{(\mathrm{L} / \mathrm{n}) \times \sum_{\mathrm{i}=1}{ }^{\mathrm{n}}[\mathrm{NPV}(\mathrm{L}) / \mathrm{L}]_{\mathrm{i}}\right\}
$$

Constraint condition:

$$
\mathrm{L}_{\max } \geq \mathrm{L} \geq \mathrm{L}_{\min }
$$

When the NPV/L of a single well reached the maximum, the total NPV of the project portfolio will get their greatest value. As for the constraint conditions in this model, they are the same as model A except for the special efficiency constrain.

Under this condition, the number $n$ of horizontal wells is known, in fact, it is the number of horizontal wells that is need to be defined, if defined, the optimal length will be worked out. The problem can be solved by iteration method with the help of an automated analysis.

\section{Model Analysis}

In model $\mathrm{A}$, the special constraint is $\{\mathrm{dNPV}(\mathrm{L}) / \mathrm{dL}\}_{\mathrm{H}} \geq(\mathrm{dNPV} / \mathrm{dL})_{\mathrm{V}}$, while the farthest position can be expressed as:

$$
\{\mathrm{dNPV}(\mathrm{L}) / \mathrm{dL}\}_{\mathrm{H}}=(\mathrm{dNPV} / \mathrm{dL})_{\mathrm{V}}
$$

Considering the fact that the economic effect of a horizontal well is always greater than that of a vertical one, this could be expressed as:

$$
\{\mathrm{NPV}(\mathrm{L}) / \mathrm{L}\}_{\mathrm{H}} \geq(\mathrm{NPV} / \mathrm{L})_{\mathrm{V}}
$$

As for vertical wells, its $\mathrm{dNPV} / \mathrm{dL}$ is equal to its NPV/L, i.e.:

$$
\{\mathrm{dNPV} / \mathrm{dL}\}_{\mathrm{V}}=(\mathrm{NPV} / \mathrm{L})_{\mathrm{V}}
$$

Combining the three equations and inequation above, we can derive the following inequation:

$$
\{\mathrm{NPV}(\mathrm{L}) / \mathrm{L}\}_{\mathrm{H}} \geq\{\mathrm{dNPV}(\mathrm{L}) / \mathrm{dL}\}_{\mathrm{H}}
$$

The above inequation is what model A should satisfy.

In addition to the description above, the curve $\mathrm{dNPV}(\mathrm{L}) / \mathrm{dL} \sim \mathrm{L}$ intersects the curve $\mathrm{NPV}(\mathrm{L}) / \mathrm{L} \sim \mathrm{L}$ just at its maximum point. It is demonstrated from Figure 2 that the optimal length $\mathrm{L}$ must lie at the right side of the curve $\mathrm{NPV}(\mathrm{L}) / \mathrm{L} \sim \mathrm{L}$ in order for the above inequation $\{\mathrm{NPV}(\mathrm{L}) / \mathrm{L}\}_{\mathrm{H}} \geq\{\mathrm{dNPV}(\mathrm{L}) / \mathrm{dL}\}_{\mathrm{H}}$ to be satisfied. In model $\mathrm{B}$, its objective function is $N P V(L) / L$, so the optimal length $\mathrm{L}$ obtained from the model is at the maximum point of the curve $\operatorname{NPV}(\mathrm{L}) / \mathrm{L} \sim \mathrm{L}$, while the optimal length $\mathrm{L}$ got from model $\mathrm{A}$ is always on its right side. Therefore the optimal length $\mathrm{L}$ from model $\mathrm{A}$ is always greater than that from model $\mathrm{B}$, which means that the optimal horizontal wellbore length of horizontal wells which were placed together with vertical wells will always be longer than that of horizontal wells drilled distinctively.

Furthermore, it can be seen from Figure 2 that the curve $\mathrm{dNPV}(\mathrm{L}) / \mathrm{dL} \sim \mathrm{L}$ of a horizontal well intersects the line 
$\mathrm{dNPV}(\mathrm{L}) / \mathrm{dL} \sim \mathrm{L}$ of a vertical well twice, i.e. the constraint $\{\mathrm{dNPV}(\mathrm{L}) / \mathrm{dL}\}_{\mathrm{H}}=(\mathrm{dNPV} / \mathrm{dL})_{\mathrm{V}}$ happened twice, but the only time they intersect on the right side of the curve is true for the optimal length. Therefore, when the constraint $\{\mathrm{dNPV}(\mathrm{L}) / \mathrm{dL}\}_{\mathrm{H}} \geq(\mathrm{dNPV} / \mathrm{dL})_{\mathrm{V}}$ is imposed on model $\mathrm{A}$, the point on the right side of the curve must be stated by the slope of the curve, i.e., $\mathrm{d}^{2}\left\{\mathrm{NPV}_{\mathrm{H}}(\mathrm{L})\right\} / \mathrm{dL}^{2}<0$, in order to get the highest optimal value.

\section{Example}

It is necessary to give emphasis at the beginning that the research paper is aimed to explain the optimal method plan to be applied on horizontal wellbore design instead of designing a specific horizontal well. Therefore, simplifying some complicated problems is allowed under the condition that it is beneficial to explain the principle much more clearly rather than distorting the basic principle of the optimal design method. In this way, data gathered from test results are not accurate enough for design reference but for the thorough explanation of the basic principle of the methodology.

In addition, the oil-reservoir is supposed to be of homogeneity through the paper. As for the unhomogeneity issue, I will discuss it specially later on.

Insert Table 1 Here

The data concerned is listed in Table 1, and the reservoir numerical simulation can forecast the oil production. As for the drilling cost, it is calculated according to the reference paper (Yueting,1994, pp81-86) and the inequality within economic life between horizontal wells and vertical wells is dealt as per the reference paper(Yueting,1997,pp117-121). The data results are listed in Table 2.

Insert Table 2 Here

It can be seen from Table 2 that if only horizontal wells are drilled, the optimal length will be 3,711.2 ft, and if both horizontal wells and vertical wells are drilled, the optimal length will be 4,670.6 ft instead of 5,303.1ft. For the reason that if the horizontal wellbore is stopped at the length of 4,670.6 ft and begin to drill vertical wells instead, the increment of NPV will be $1.04 \times 10^{7} \$\left((5203.1-4670.6) \times 19,473.5=10,369,638.75 \$ \approx 1.04 \times 10^{7} \$\right)$, which is greater than the value of continuously drilling the horizontal wellbore up to 5,303.1ft, which is $9.52 \times 10^{6} \$\left(\left(1.1197 \times 10^{8}-1.0245 \times 10^{8}\right)=9.52 \times 10^{6}\right)$. In addition, it can be seen from Table 2 that the NPV/L of horizontal wellbore with length of $3,711.2 \mathrm{ft}$ is the greatest among the three maximum values. Therefore, in order to obtain the maximum value of NPV of a certain oil reservoir, this reservoir needs to be better developed by horizontal wells as much as possible, and their optimal length should be $3,711.2 \mathrm{ft}$. If only a few horizontal wells are placed among a large number of vertical wells, the optimal length of the horizontal well should not exceed 4,670.6 ft, which is the highest optimal horizontal length of this case, and the length of 5,303.1ft is not the optimal horizontal length but the maximum length, plus its NPV will be diminishing instead of amplifying.

\section{Conclusions}

The optimal horizontal wellbore length does exist. It is both necessary and feasible to work out the optimal horizontal wellbore length when a long horizontal well is designed, otherwise the horizontal wellbore may be drilled exceeding the optimal value.

The length that the NPV of a horizontal well gets its maximum value is not the economically optimal length but the upper limit. If the NPV of a horizontal well is taken as the objective function when its optimal length is designed, the farther efficiency constraint must impose upon it. Otherwise, it will yield a length too long to be at the optimal value.

Depending on the effect from internal and external factors, different horizontal wells may have different optimal lengths. Basing on quantification, the optimal length of horizontal wells drilled together with vertical wells is always longer than that of horizontal wells that are drilled distinctively. In addition, even though there are vertical wells being drilled, if only horizontal wells are drilled within a certain area, the optimal length design of the horizontal well should follow model B in order to get the maximum value of NPV of a certain oil reservoir development. Only in the case that one or two horizontal wells are drilled along with a large number of vertical wells, can the optimal length design of the horizontal well follow model A.

\section{References}

Dikken B. J. (1990). Pressure Drop in Horizontal Wells and Its Effects on Their Production Performance. JPT, November, 90-94.

Guanmin Liang. (2008). The Study on Optimal Horizontal Wellbore Design, Paper of applying for the master degree of Petroleum University of China. 
Hyun Cho. (2003). Integrated Optimization on a Long Horizontal Well Length. SPE 83669, April.

Jiaji Fu \& Yunhuan Tong. (1997). Industrial Engineering Economics (3rd Edition). Tsinghua University Press, Beijing, (Chapter 3).

Moritis, G.. (1990). Horizontal Drilling Scores More Successes, Oil \& Gas Journal. Special, February, 67-71.

Novy, R.A. (1995). Pressure Drops in Horizontal Wells: Can They Be Ignored? SPE, February.

Yueting Hu. (1994). A Method for Predicting Horizontal Well Drilling Cost, Petroleum Drilling Technique. No.3, 81-85.

Yueting Hu. (1995). On the Best Investment Scale of Construction projects, Journal of Peking University (Philosophy and Social Science). July 92-96.

Yueting Hu. (1997). A Comparative Evaluation on Economic Effect of Horizontal Well and Vertical Well, ACTA PETROLEI SINICA. No.4, 117-121.

Yueting Hu. (2010). On the Design Method of Economically Optimal Scale of Projects, International Journal of Economics and Finance. No.1, 210-217.

Zhifei Fan, Hongchang Fang. (1997). On the Design Method of Optimal Horizontal Wellbore. ACTA PETROLEI SINICA, No.1, 70-75.

Table 1. Data of the Example

\begin{tabular}{|l|c|c|l|c|c|}
\hline \multicolumn{4}{|c|}{ The reservoir parameter } & \multicolumn{3}{c|}{ The economic parameter } \\
\hline \multicolumn{1}{|c|}{ parameter } & quantity & unit & \multicolumn{1}{c|}{ parameter } & quantity & unit \\
\hline Radius of drainage & 660 & feet & Appraisal time & 10 & year \\
\hline Radius of wellbore & 4.25 & inch & Basic return of rate & 10 & $\%$ \\
\hline Vertical permeability & 2 & $\mathrm{md}$ & Oil price & 25 & $\$ / \mathrm{bbl}$ \\
\hline Horizontal permeability & 20 & $\mathrm{md}$ & Vertical well operating cost & 100 & $\$ /$ day \\
\hline Porosity & 20 & $\%$ & $\begin{array}{l}\text { Horizontal well operating } \\
\text { cost }\end{array}$ & 200 & $\$ /$ day \\
\hline Depth of oil reservoir & 40 & foot & & & \\
\hline Viscosity & 3 & $\mathrm{cp}$ & & & \\
\hline Drainage pressure & 1200 & $\mathrm{lbf} / \mathrm{in}^{2}$ & & & \\
\hline
\end{tabular}

Table 2. The Results of the Example

\begin{tabular}{|c|c|c|c|c|c|}
\hline Program* & $\begin{array}{c}\text { The objective } \\
\text { function }\end{array}$ & Special constraint & $\begin{array}{c}\text { Horizontal } \\
\text { wellbore } \\
\text { length }(\mathrm{ft})\end{array}$ & $\begin{array}{c}\text { NPV } \\
\text { per well } \\
(\$)\end{array}$ & $\begin{array}{c}\text { NPV } \\
\text { per meter } \\
(\$ / \mathrm{ft})\end{array}$ \\
\hline 1 & $\operatorname{Max}\{\mathrm{NPV}(\mathrm{L}) / \mathrm{L}\}$ & -- & 3711.2 & $8.1863 \times 10^{7}$ & 22058.4 \\
\hline 2 & $\operatorname{Max}\{\mathrm{NPV}(\mathrm{L})\}$ & $\{\mathrm{dNPV}(\mathrm{L}) / \mathrm{dL}\} \mathrm{H} \geq 19473.5$ & 4670.6 & $1.0245 \times 10^{8}$ & 21935.1 \\
\hline 3 & $\operatorname{Max}\{\mathrm{NPV}(\mathrm{L})\}$ & -- & 5303.1 & $1.1197 \times 10^{8}$ & 21114.1 \\
\hline 4 & (Vertical well) & -- & $(1320)$ & $2.5705 \times 10^{7}$ & 19473.5 \\
\hline
\end{tabular}

*Note: Program 1 is the case wherein only horizontal wells are drilled, while Program 4 is the case wherein only vertical wells are drilled. Program $2 \& 3$ are the cases wherein both the vertical wells and the horizontal wells are drilled, and the difference between Programs 2 \& 3 is that there is a special constraint that the $d N P V(L) / d L$ of a horizontal well must be no less than that of a vertical well is added in the model of Program 2. 


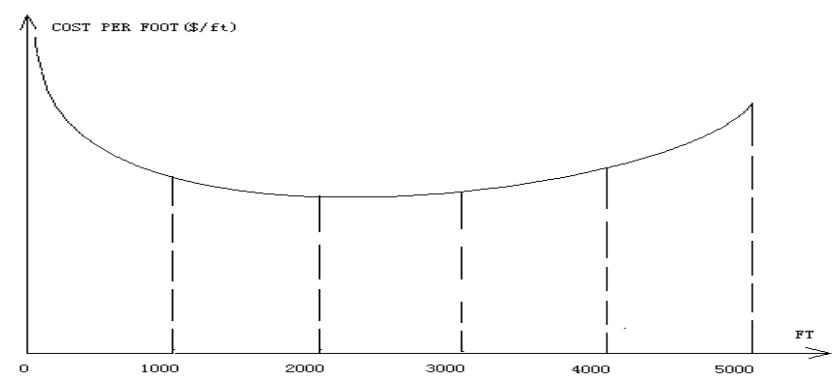

Figure 1. Census curve of the drilling cost per foot vs. the horizontal wellbore length

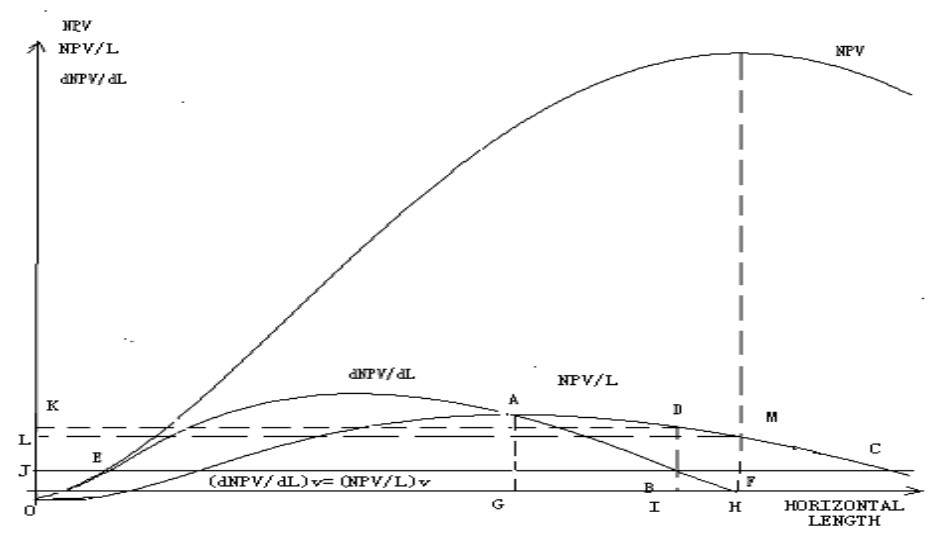

Figure 2. Relationship among NPV, NPV/L \& dNPV/dL 